\title{
Comparison of the Antifungal Efficacy of Four Concentrations of Minthostachys mollis (Muña) Essential Oil against Candida albicans: An In Vitro Study
}

\author{
Kevin Huamani ${ }^{1}$, Luzmila Vilchez ${ }^{2}$, Franco Mauricio ${ }^{3}$, Hilda Jáuregui ${ }^{4}$, Arnaldo Munive-Degregori ${ }^{5}$, Frank Mayta-Tovalino ${ }^{6}$
}

\begin{abstract}
Aim and objective: This paper aims to compare the antifungal efficacy of four concentrations of Minthostachys mollis essential oil (MEO) against Candida albicans ATCC 10231.

Materials and methods: This study was conducted in vitro. Ten kilograms of M. mollis (Muña) were collected in the city of Tarma, Peru. The plant was then dried in the shade at room temperature $\left(21^{\circ} \mathrm{C}\right)$, and the essential oil was obtained through distillation. C. albicans ATCC 10231 was cultured at a MacFarland scale of 0.5 , which corresponds to a concentration of $3 \times 10^{8} \mathrm{CFU} / \mathrm{mL}$. Each plate was filled with one of the four MEO concentrations $(25,50,75$, or $100 \%)$, dimethyl sulfoxide (negative control), or fluconazole (positive control), a known antifungal agent. After incubation, each plate was examined using the Kirby-Bauer method.

Results: Compared to MEO 25\%, MEO 50\%, and MEO 75\%, MEO $100 \%$ had the highest antifungal efficacy at 24, 48 , and 72 hours of evaluation, with an average of $18.9 \pm 0.7,18.2 \pm 0.7$, and $17.0 \pm 0.4 \mathrm{~mm}$, respectively. However, fluconazole had higher efficacy $(27.9 \pm 0.5,27.5 \pm 0.5$, and $23.7 \pm 0.7 \mathrm{~mm}$, respectively). Post hoc analysis showed that there were significant differences between all concentrations of the MEO groups and their respective positive and negative control groups $(p<0.001)$.

Conclusion: Among the MEO groups, the pure concentration (MEO 100\%) had the highest antifungal efficacy. However, fluconazole presented greater efficacy, and the differences were statistically significant.

Clinical significance: This research allowed to know the efficacy of this natural resource against one of the most prevalent fungi in the oral cavity. Therefore, a line of research could be opened to deepen its potential benefits for oral health.

Keywords: Antifungal efficacy, Candida albicans, Minthostachys mollis.

The Journal of Contemporary Dental Practice (2021): 10.5005/jp-journals-10024-3225
\end{abstract}

\section{INTRODUCTION}

In recent years, fungal infections have increased in frequency and importance; they are often associated with high mortality and are generally caused by bloodstream infections due to Candida species..$^{1-4}$ Worldwide, oral candidiasis prevalence rates of $32.5,83$, and $88 \%$ have been reported in patients with brain damage, denture wearers, and children with human immunodeficiency virus (HIV), respectively. Oral candidiasis is characterized by white lesions located in any region of the oral mucosa such as the tongue, floor of the mouth, tonsils, etc. These whitish lesions usually present an elevation with erythematous areas, causing pain and discomfort to speak and eat. ${ }^{2,3}$

In addition, the few drugs currently available have significant toxicity that can worsen the systemic response. In addition, in recent years, there have been reports of antifungal resistance, so it is important to identify therapeutic alternatives such as phytotherapy. Patients often gravitate toward phytotherapeutics, as they are free of synthetic and chemical additives. However, these agents lack rigorous scientific backing; therefore, it is necessary to demonstrate the therapeutic effects of phytotherapeutics considering the wellbeing and safety of the patient. ${ }^{4,5}$

Muña, scientifically known as Minthostachys mollis, is an aromatic shrub native to South America and of great pharmacological interest because of its essential oils. ${ }^{6-8}$ In the Andes, it is used not only as a condiment or tea but also as popular medicinal plant; it has received increasing attention in pharmacology and modern medicine. Muña is a folkloric plant that is often used to treat decompensation due to changes in altitude, flatulence. Its main components include
${ }^{1-3}$ Academic Department, Faculty of Dentistry, Universidad Nacional Federico Villarreal, Lima, Peru

${ }^{4}$ Academic Department, Faculty of Medicine, Universidad Nacional Federico Villarreal, Lima, Peru

${ }^{5}$ Postgraduate Department, Faculty of Dentistry, Universidad Nacional Mayor de San Marcos, Lima, Peru

${ }^{6}$ Vicerrectorado de Investigación, Universidad San Ignacio de Loyola (USIL), Lima, Peru

Corresponding Author: Frank Mayta-Tovalino, Vicerrectorado de Investigación, Universidad San Ignacio de Loyola (USIL), Lima, Peru, Phone: +51 1317 1000, e-mail: fmayta@usil.edu.pe

How to cite this article: Huamaní K, Vilchez L, Mauricio F, et al. Comparison of the Antifungal Efficacy of Four Concentrations of Minthostachys mollis (Muña) Essential Oil against Candida albicans: An In Vitro Study. J Contemp Dent Pract 2021;22(11):1227-1231.

Source of support: Nil

Conflict of interest: None

phosphorus, calcium, menthone, etc. This prodigious plant stands out for its multiple benefits for the human being; although scientific evidence is still scarce, it is attributed with certain anti-inflammatory and antimicrobial properties. ${ }^{6-10}$

However, there is little scientific evidence regarding this natural resource. Therefore, the objective of the present study was to compare the antifungal activity of different concentrations of M. mollis essential oil (MEO) against Candida albicans ATCC 10231. 


\section{Materials and Methods}

\section{Study Design}

The study was of an in vitro experimental type. Physicochemical and microbiological analyses were performed at the Analytical Control Center of the Faculty of Pharmacy and Biochemistry of the Universidad Nacional Mayor de San Marcos, Lima-Peru. The sample size was calculated from a mean comparison formula, where a confidence level of $95 \%$ and power of $80 \%$ were considered. The mean and standard deviation parameters were obtained from a previous pilot study. A total of 84 specimens were determined, divided among the seven groups as follows: Group I, MEO 25\%; Group II, MEO 50\%; Group III, MEO 75\%; Group IV, MEO 100\%; Group V, Fluconazole; Group VI, Dimethyl sulfoxide; and Group VII, distilled water.

\section{Specimen Preparation}

Ten kilograms of $M$. mollis (Muña) plant were collected in the city of Tarma (location $11^{\circ} 2444^{\prime \prime} \mathrm{S} 75^{\circ} 4104^{\prime \prime} \mathrm{W}$ ) in the Department of Junín, Peru (Fig. 1A). The study of the plant was carried out by the Faculty of Pharmacy and Biochemistry (CENPROFAMRA) of the Universidad Nacional Mayor de San Marcos, with the following classification:

- Division: Magnoliophyta

- Class: Magnoliopsida

- Subclass: Asteridae

- Order: Verbenales

- Family: Lamiaceae

- Genus: Minthosthachys (Benth.) Spach

- Species: clinopodium

The plant was then dried under shade at room temperature for 7 days, until the dry sample was obtained. The essential oil was obtained by the steam entrainment method. For which, the solvent diethyl ether $\left(\mathrm{C}_{2} \mathrm{H}_{5}\right)_{2} \mathrm{O}$ was used to obtain the separation using water vapor volatilizing the components of the vegetable matter. The samples were then preserved in hermetically sealed bags for transport to the laboratory. The dried leaves were selected and subjected to steam distillation in a distillation system consisting of an 8-L boiler, hopper, refrigerant and connection hoses; water and oil were obtained after 3 hours of distillation. Considering its immiscibility properties and the difference in density between water and the essential oil, the distillate was separated using a glass decanting funnel. Finally, $10 \mathrm{~mL}$ of $M$. mollis essential oil was obtained and stored in an amber-colored glass bottle and refrigerated at $4^{\circ} \mathrm{C}$ (Fig. 1B).

\section{Culture Medium}

Ten milliliters of Sabouraud broth (30 $\mathrm{g}$ for $1 \mathrm{~L}$ of distilled water) were prepared in a test tube and autoclaved. Fifty milliliters of Sabouraud agar was prepared for the activation phase $(52 \mathrm{~g}$ for $1 \mathrm{~L}$ of distilled water). The sterilized agar was then cooled in a water bath at $45-50^{\circ} \mathrm{C}$ and poured into sterile Petri dishes. Then, $900 \mathrm{~mL}$ of Mueller Hinton agar was prepared for the analytical phase. Once tempered, the preparation was poured into sterile glass Petri dishes to give a uniform bottom of approximately $4 \mathrm{~mm}$, corresponding to 25-30 $\mathrm{mL}$ for $90 \mathrm{~mm}$ diameter plates. The plated agar was allowed to solidify at room temperature.

\section{Strain Reactivation}

The strain was refrigerated at $4-8^{\circ} \mathrm{C}$. A colony was taken with the seeding loop into a tube with sterile Sabouraud broth and placed in an incubator at $35^{\circ} \mathrm{C}$ for 24 hours. Turbidity showed growth in the strains. Sabouraud broth was seeded onto plates with Sabouraud agar. The mixture was incubated at $35^{\circ} \mathrm{C}$ for 24 hours. Pure colonies of C. albicans ATCC 10231 were diluted in a test tube containing $10 \mathrm{~mL}$ of sterile saline $(0.9 \%$ sodium chloride), so that the resulting solution had a turbidity corresponding to the McFarland scale of 0.5 , which represents a concentration of $3 \times 10^{8} \mathrm{CFU} / \mathrm{mL}$.

\section{Inoculation and Seeding}

One hundred microliters of the prepared inoculum $\left(1 \times 10^{8} \mathrm{CFU} / \mathrm{mL}\right)$ were added to the plates with Mueller Hinton agar. Using a Drigalski spatula, the inoculum was spread throughout the plates in such a way as to obtain homogeneous growth; the loop was slid on the plate in a parallel and compact manner, covering the entire surface of the plate. The procedure was repeated by rotating the plate $60^{\circ}$ two more times. The plates were carefully seeded from edge to edge to prevent difficulty when taking readings. The plates were allowed to dry for 3-5 minutes before the wells were made. The punch was sterilized and flamed in a burner to make the wells. The wells should be more than $15 \mathrm{~mm}$ from the edge of the plate and should be distributed in such a way that there is no overlap of the inhibition halos. Each group was loaded with approximately $40 \mu \mathrm{L}$ of each well. Dimethyl sulfoxide was used as a negative control, and fluconazole ( $2 \mathrm{mg} / \mathrm{mL}$ ) was used as a positive control.
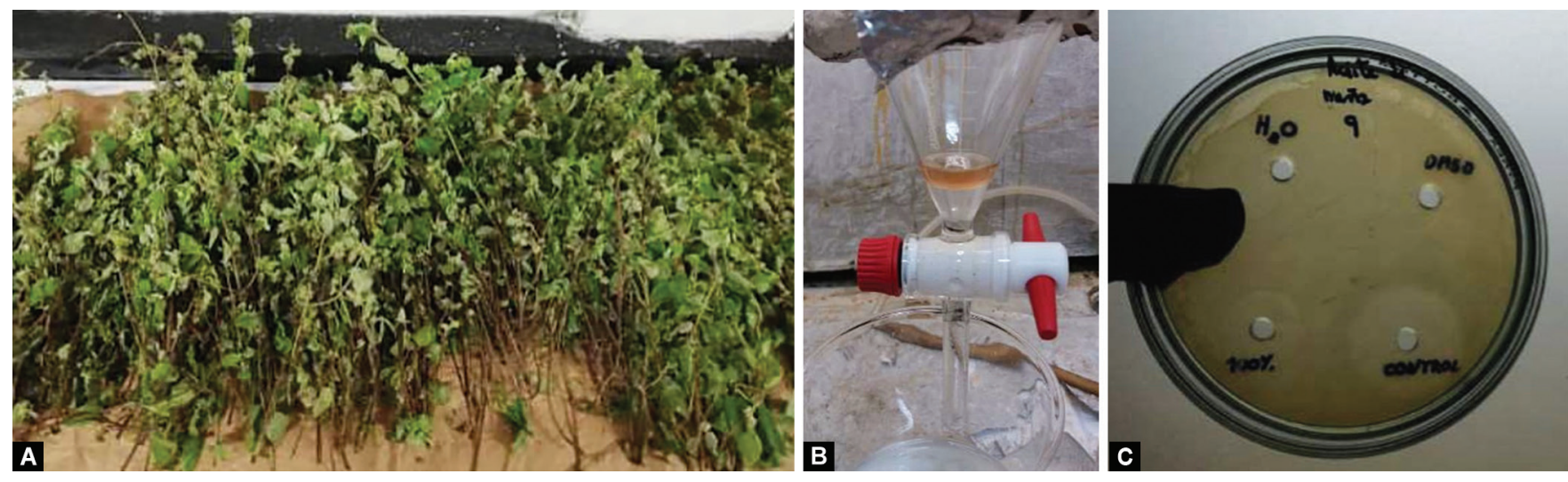

Figs 1 A to C: (A) Selection of Muña leaves; (B) Obtaining essential oil of Muña; (C) Inhibition halos of Muña essential oil 25, 50, and 75\% 


\section{Incubation and Reading}

The sample plates and controls were placed in an incubator at $35^{\circ} \mathrm{C}$ for 24,48 , and 72 hours. After incubation, each plate was examined using the Kirby-Bauer method (Fig. 1C). The resulting inhibition zones were uniformly circular in a homogeneous layer of microbial growth. The diameters of the complete inhibition zone were measured in millimeters and passed through the center of each well. Measurements were performed in triplicate for each well using a digital vernier (Mitutoyo, Japan). The values of the measurements were averaged and rounded to the nearest natural number.

\section{Statistical Analysis}

A descriptive analysis of the data was performed, presenting summary measures (mean and standard deviation) for each group. The normality of the data for each group was evaluated using the shapiro-wilk test. Comparative analysis between groups was performed using ANOVA. A multivariate linear regression analysis was then performed. All analyses were interpreted by establishing a $p<0.05$, using the Stata ${ }^{\circledR} 15$ statistical software.

\section{Results}

Compared to other concentrations, MEO $100 \%$ had the highest antifungal efficacy at 24,48 , and 72 hours of evaluation, with an average of $18.9 \pm 0.7,18.2 \pm 0.7$, and $17.0 \pm 0.4 \mathrm{~mm}$, respectively. However, fluconazole had higher efficacy $(27.9 \pm 0.5,27.5 \pm 0.5$, and
$23.7 \pm 0.7 \mathrm{~mm}$, respectively). All groups had a normal distribution $(p>0.05)$. The comparative analysis showed that there were significant differences between all the antifungal efficacies of all concentrations of MEO and fluconazole $(p<0.001)$ (Table 1).

The post hoc analysis showed that there were significant differences between all concentrations of MEO groups and their respective positive and negative control groups $(p<0.001)$ (Table 2).

The mean of antifungal efficacy was $3.3 \mathrm{~mm}$ more ( $\mathrm{Cl}: 2.9-3.7)$ for MEO $50 \%$ compared to MEO 25\%. The average antifungal efficacy was $5.7 \mathrm{~mm}$ more (Cl: 5.3-6.1) in MEO 75\% compared to MEO 25\%. The average antifungal efficacy was $9.8 \mathrm{~mm}$ more (Cl: $9.4-10.2)$ in MEO $100 \%$ compared to MEO $25 \%$. Finally, the mean antifungal efficacy was $18.8 \mathrm{~mm}$ more (Cl: 18.4-19.2) in fluconazole compared to MEO $25 \%$. All groups were statistically significant $(p<0.001)$ (Table 3).

\section{Discussion}

Oral candidiasis is a common fungal disease usually caused by an overgrowth of C. albicans in the oral cavity. Recommended treatments include proper oral hygiene, use of topical agents, and systemic medications. ${ }^{11,12}$ The widespread use of antifungals both prophylactically and therapeutically has led to the emergence of secondary resistance and the displacement of sensitive strains by more resistant ones. ${ }^{13-15}$

Table 1: Comparison of the antifungal effect of MEO in different concentrations

\begin{tabular}{|c|c|c|c|c|c|c|c|c|c|c|c|c|c|c|c|c|}
\hline & \multicolumn{2}{|c|}{ MEO 25\% } & \multicolumn{2}{|c|}{ MEO 50\% } & \multicolumn{2}{|c|}{ MEO 75\% } & \multicolumn{2}{|c|}{ MEO 100\% } & \multicolumn{2}{|c|}{ Fluconazole } & \multicolumn{2}{|c|}{ Dimethylsulfoxide } & \multicolumn{2}{|c|}{ Distilled water } & \multirow[b]{2}{*}{$p^{*}$} & \multirow[b]{2}{*}{$p^{* *}$} \\
\hline & Mean & $S D$ & Mean & $S D$ & Mean & $S D$ & Mean & $S D$ & Mean & $S D$ & Mean & $S D$ & Mean & $S D$ & & \\
\hline 24 hours & 9.1 & 0.5 & 12.4 & 0.7 & 14.8 & 0.5 & 18.9 & 0.7 & 27.9 & 0.5 & 6 & 0 & 6 & 0 & 0.05 & 0.01 \\
\hline 48 hours & 8.3 & 0.5 & 12.1 & 0.5 & 14.4 & 0.5 & 18.2 & 0.7 & 27.5 & 0.5 & 6 & 0 & 6 & 0 & 0.05 & 0.01 \\
\hline 72 hours & 7.3 & 0.5 & 9.0 & 2.7 & 12.4 & 0.7 & 17.0 & 0.4 & 23.7 & 0.7 & 6 & 0 & 6 & 0 & 0.05 & 0.01 \\
\hline
\end{tabular}

MEO, minthostachys mollis essential oil; ${ }^{*}$ Shapiro wilk test; ${ }^{* *}$ ANOVA test

Table 2: Post hoc analysis of antifungal effect of MEO

\begin{tabular}{lcccccc}
\hline Groups & MEO 25\% & MEO 50\% & MEO 75\% & MEO 100\% & Fluconazole & Dimethylsufoxide \\
\hline MEO 50\% & 0.001 & - & - & - & - & - \\
MEO 75\% & 0.001 & 0.001 & - & - & - & - \\
MEO 100\% & 0.001 & 0.001 & 0.001 & - & - & - \\
Fluconazole & 0.001 & 0.001 & 0.001 & 0.001 & - & - \\
Dimethylsufoxide & 0.001 & 0.001 & 0.001 & 0.001 & 0.001 & - \\
Distilled water & 0.001 & 0.001 & 0.001 & 0.001 & 0.001 & 0.001 \\
\hline
\end{tabular}

MEO, minthostachys mollis essential oil

Table 3: Linear regression of the antifungal effect of MEO

\begin{tabular}{lrrrcc}
\hline Antifungal efficacy & Coef. & Std. Err. & $p$ & [95\% confidence interval] \\
\hline MEO 25\% & Ref. & & & & \\
MEO 50\% & 3.3 & 0.2 & 0.001 & 2.9 & 3.7 \\
MEO 75\% & 5.7 & 0.2 & 0.001 & 5.3 & 6.1 \\
MEO 100\% & 9.8 & 0.2 & 0.001 & 9.4 & 10.2 \\
Fluconazole & 18.8 & 0.2 & 0.001 & 18.4 & 19.2 \\
Dimethylsulfoxide & -3.1 & 0.2 & 0.001 & -3.5 & -2.7 \\
Distilled water & -3.1 & 0.2 & 0.001 & -3.5 & -2.7 \\
_cons & 9.1 & 0.1 & 0.001 & 8.8 & 9.4 \\
\hline
\end{tabular}

MEO, minthostachys mollis essential oil 
Peru has an abundant plant diversity, including medicinal plants with established antibacterial and antifungal properties, such as M. mollis or "Muña." ${ }^{1,10}$ This study aimed to evaluate the efficacy of $M$. mollis essential oil as an alternative to fluconazole.

According to a study by Cano et al., ${ }^{16}$ monoterpenes and other compounds in Muña essential oil inhibited M. canis and Trichophyton tonsurans and showed an inhibition diameter of up to $30 \mathrm{~mm}$ for the pure (100\%) concentration. These results coincide with our findings, which showed an antifungal efficacy around $18.9 \mathrm{~mm}$. Moreover, according to a study by Peña et al., ${ }^{17}$ M. mollis essential oil from Huancavelica, Peru, not only has antifungal efficacy but also antibacterial efficacy against $S$. aureus and Klebsiella pneumoniae. These findings also coincide with a study by Torrenegra-Alarcon et al., ${ }^{18}$ which identified bacteria sensitive to $M$. mollis essential oil due to the high monoterpene content. Therefore, this plant species is promising for the control of bacterial pathogens.

Another study conducted by Alcalá et al. ${ }^{19}$ reported that pure M. mollis essential oil (100\%) was more effective against C. albicans strains than fluconazole and that the antifungal effect of fluconazole was greater than that of $M$. mollis $25 \%$, which was the same as that of $M$. mollis $50 \%$. However, our results showed some variance; all concentrations (25, 50, 75 and $100 \%)$ had a lower mean compared to fluconazole.

Another important study was conducted by Alcalá et al. ${ }^{19}$ who mentioned that the essential oil of $M$. mollis (100\%) was more effective against $C$. albicans strains than fluconazole, in addition, the antifungal effect of fluconazole was greater than that of $M$. mollis $25 \%$ and was the same as that of $M$. mollis $50 \%$. However, our results were different since all our concentrations $(25,50,75$, and $100 \%)$ had lower mean compared to Fluconazole.

The main limitation of this study was the scarce scientific evidence on the antifungal efficacy of this natural resource in the field of oral health. So, it is difficult to discuss the similarities and differences between studies. ${ }^{20}$ This is probably since this natural resource is a plant native to the high Andean zones of South America, which makes it difficult to carry out studies in other continents. Another limitation was that only the antifungal efficacy against one strain (C. albicans) was evaluated; it would be useful to evaluate other fungi. In this way, the spectrum of action of Muña could be broadened.

The future direction of this study is its contribution to scientific knowledge. By demonstrating the antifungal efficacy of $M$. mollis, our findings allow us to consider this plant a natural source with antifungal potential and thus apply it in the future as an accessible therapeutic alternative to treat $C$. albicans infections.

\section{Conclusion}

All concentrations of MEO were effective against $C$. albicans; but the pure concentration (MEO 100\%) showed the highest antifungal efficacy among the experimental groups. However, fluconazole presented greater efficacy, and these differences were statistically significant.

\section{ACKnOWLedgments}

The authors wish to thank the Universidad Federico Villarreal and the Universidad San Ignacio de Loyola for their constant support in the preparation and revision of this manuscript.

\section{References}

1. Lortholary O, Renaudat C, Sitbon K, et al. French Mycosis Study Group. Worrisome trends in incidence and mortality of candidemia in intensive care units (Paris area, 2002-2010). Intensive Care Med 2014;40(9):1303-1312. DOI: 10.1007/s00134-014-3408-3.

2. Gaitán-Cepeda LA, Sánchez-Vargas O, Castillo N. Prevalence of oral candidiasis in HIV/AIDS children in highly active antiretroviral therapy era. A literature analysis. Int J STD AIDS 2015;26(9):625-632. DOI: $10.1177 / 0956462414548906$.

3. Odgaard L, Kothari M. Prevalence and association of oral candidiasis with dysphagia in individuals with acquired brain injury. Brain Inj 2018;32(2):247-251. DOI: 10.1080/02699052.2017.1407960.

4. Mora FD, Araque M, Rojas LB, et al. Chemical composition and in vitro antibacterial activity of the essential oil of Minthostachys mollis (Kunth) Griseb Vaught from the Venezuelan Andes. Nat Prod Commun 2009;4(7):997-1000. DOI: 10.1177/1934578X0900400726.

5. Rojas-Armas JP, Arroyo-Acevedo JL, Ortiz-Sánchez JM, et al. Corrigendum to "potential toxicity of the essential oil from Minthostachys mollis: a medicinal plant commonly used in the traditional Andean medicine in Peru". J Toxicol 2020;2020:2103456. DOI: $10.1155 / 2020 / 2103456$.

6. Schmidt-Lebuhn AN. Ethnobotany, biochemistry and pharmacology of Minthostachys (Lamiaceae). J Ethnopharmacol 2008;118(3):343-353. DOI: 10.1016/j.jep.2008.05.030.

7. Linares-Otoya V. Considerations for the use and study of the Peruvian "muña" Minthostachys mollis (Benth.) Griseb and Minthostachys setosa (Briq.) Epling. Ethnobotany Res Appl 2020;19. Available from: http:// dx.doi.org/10.32859/era.19.29.1-9.

8. Castro-Alayo EM, Chávez-Quintana SG, Auquiñivín-Silva EA, et al. Essential oils of native plants from Peru: effect of the place of cultivation on the physicochemical characteristics and antioxidant activity. Scientia Agropecu 2019;10(4):479-487. DOI: 10.17268/ sci.agropecu.2019.04.04.

9. Calderon A, Salas J, Dapello G, et al. Assessment of antibacterial and antifungal properties and in vivo cytotoxicity of Peruvian Passiflora mollisima. J Contemp Dent Pract 2019;20(2):145-151. DOI: 10.5005/ jp-journals-10024-2489.

10. Mayta-Tovalino F, Gamboa E, Sánchez R, et al. Development and formulation of the experimental dentifrice based on Passiflora mollissima (Tumbo) with and without Fluoride Anion: antibacterial activity on seven antimicrobial strains. Int J Dent 2019;2019:9056590. DOI: $10.1155 / 2019 / 9056590$.

11. Alegre A, lannacone J, Carhuapoma M. Toxicity of aqueous, ethanolic and hexanic extracts of Annona muricata, Minthostachys mollis, Lupinus mutabilis, and Chenopodium quinoa against Tetranychus urticae and Chrysoperla externa. Chil J Aric Anim Sci 2017;33(3): 273-284. Available from: https://www.researchgate.net/ publication/321768954.

12. Banchio E, Zygadlo J, Valladares GR. Effects of mechanical wounding on essential oil composition and emission of volatiles from Minthostachys mollis. J Chem Ecol 2005;31(4):719-727. DOI: 10.1007/ s10886-005-3540-1.

13. Lock O, Perez E, Villar M, et al. Bioactive compounds from plants used in Peruvian traditional medicine. Nat Prod Commun 2016;11(3): 315-337. Available from: https://www.researchgate.net/ publication/301583788.

14. Pellegrini MC, Alonso-Salces RM, Umpierrez ML, et al. Chemical composition, antimicrobial activity, and mode of action of essential oils against Paenibacillus larvae, etiological agent of American Foulbrood on Apis mellifera. Chem Biodivers 2017;14(4):1-18. DOI: $10.1002 / c b d v .201600382$.

15. Fernández MC, Fárez DLA, Roblez NCC, et al. Chemical composition and antibacterial activity of the essential oil of Minthostachys mollis Griseb against Staphylococcus aureus. Rev Cuba Farm 2017;51(4). Available from: http://www.revfarmacia.sld.cu/index.php/far/article/ view/183. 
16. Cano $C$, Bonilla $P$, Roque $M$, et al. In vitro antifungal activity pand metabolites of the essential oil of Minthostachys mollis (muña) leaves. Rev Peru Med Exp Salud Publica 2008;25(3):298-301. Available from: http://www.scielo.org.pe/scielo.php?pid=S1726-46342008000300 008\&script=sci_abstract\&tlng=en.

17. Peña D, Gutiérrez M. Antimicrobial effect of the essential oil of Minthostachys mollis on frequent microorganisms in the lower respiratory tract. Rev Cienc Tecnol 2017;13(3):55-66. Available from: https://revistas.unitru.edu.pe/index.php/PGM/article/ view/1874.

18. Torrenegra-Alarcón M, Granados-Conde C, Durán-Lengua M, et al. Composición Química y Actividad Antibacteriana del Aceite
Esencial de Minthostachys mollis. Orinoquia 2016;20(1):69-74. DOI: 10.22579/20112629.329.

19. Alcalá KM, Alvarado AG, Alejandro LA, et al. Actividad antimicótica del aceite esencial de las hojas de Minthostachys mollis (muña) comparado con el fluconazol en cultivo de Candida albicans. Ciencia e Investigación Médico Estudiantil Latinoamericano 2011;16(2):83-86. Available from: https://www.cimel.felsocem.net/index.php/CIMEL/ article/view/204.

20. Poma-Castillo L, Espinoza-Poma M, Mauricio F, et al. Antifungal activity of ethanol-extracted Bixa orellana (L) (Achiote) on Candida albicans, at six different concentrations. J Contemp Dent Pract 2019;20(10):1159-1163. DOI: 10.5005/jp-journals-10024-2672. 